\title{
Breve referencia a la política de las grandes ciudades y de las áreas metropolitanas en Portugal
}

\section{Fernanda Paula O liveira*}

\section{Reflexiones introductorias}

La problemática de las grandes ciudades y de las metrópolis tiene una importancia fundamental en la actual Ciencia de la Administración y en el moderno D erecho Administrativo, planteando desafíos complejos y exigentes, tanto desde el punto de vista de la gestión del territorio, como de la competitividad, así como de la propia participación ciudadana.

Este problema se originó a causa del fenómeno de concentración y crecimiento desmesurado de las poblaciones en las áreas urbanas: no existen dudas de que a partir de una cierta dimensión los problemas que surgen en las grandes ciudades pasan a ser específicos y distintos de aquellos que surgen en las restantes ciudades y municipios que no alcanzan esta dimensión. En Portugal tales problemas son, probablemente, la progresiva tercerización y «expulsión» de la vivienda en los núcleos centrales de las principales aglomeraciones urbanas, lo que supone una sobreutilización de las redes de infraestructuras, normalmente viarias, durante las horas de trabajo y la desertización de la ciudad en cuanto espacio de vivencia urbana en los periodos post-laborales; 0 el desarrollo poco racional en términos económicos de las redes de equipamientos y de infraestructuras urbanas provo- cado por la apertura de nuevos frentes de urbanización, frecuentemente subequipados, en detrimento de los sistemas existentes; 0 de la carencia de terrenos para equipamientos colectivos, infraestructuras urbanas, espacio público, viviendas a precios tasados y para una eventual permuta con privados, en el ámbito de adquisición de solares o/y edificios para proyectos de desarrollo y renovación urbana; 0 de los transportes que consumen una parte significativa de la vida de las personas que trabajan en los grandes centros urbanos; los problemas provocados por la existencia de un paisaje urbano agresivo y deshumanizado, debido, probablemente, al crecimiento anárquico y a la especulación de los terrenos y de las fincas urbanas; por último, el problema de la fuerte concentración espacial de situaciones de pobreza, desintegración, rotura de lazos de cohesión social, pérdida de sociabilidad y de ciudadanía, segregación social, desempleo y marginalidad, que se manifiestan en la existencia de espacios urbanos extremadamente desvalorizados en el centro de la ciudad 0 en sus periferias 1.

Como afirma Freitas do Amaral${ }^{2}$, el fenómeno de las grandes ciudades se divide en tres tipos de problemas: los relativos a la gran ciudad considerada en sí misma, los relativos al área metropolitana formada por la gran ciudad y los territorios vecinos que la circundan y que constituyen su esfera de influencia; y los relativos a la organización administrativa de los núcleos urbanos satélites de la gran ciudad.

En el primer grupo de problemas, la cuestión que principalmente surge es saber cómo se debe organizar una gran 
ciudad, o sea, hasta qué punto una gran ciudad deberá tener una organización idéntica a los restantes municipios 0 , por el contrario, una estructura especial 3 . En cuanto al segundo grupo de problemas, la cuestión que surge es saber cómo articular la gran ciudad con sus al rededores, de modo que sirva mejor a la población total del área, tanto en materia de planes de urbanización, como de vivienda, transportes colectivos, servicios públicos, etc... Por fin, en lo que concierne al tercer grupo de problemas, la cuestión esencial es saber cuál es la estructura que deben tener las aglomeraciones de población que están fuera del territorio de la gran ciudad, pero que con ella constituyen una zona más amplia con problemas específicos.

Todo esto muestra cómo el problema de las grandes ciudades evoluciona rápidamente hacia el de la relación de la gran ciudad (por ejemplo, que corresponde a un municipio) con los restantes municipios que las rodean surgiendo la cuestión de las áreas metropolitanas y de las grandes áreas urbanas. La continuidad de ciertos servicios urbanos es una de las características de estas áreas que, desarrollándose en común, pueden beneficiarse de economías de escala importantes y/o proporcionar una distribución más equilibrada en varias zonas. Ésta es la razón fundamental para conceder a las grandes aglomeraciones una figura administrativa diferente de la que se impone al resto del país.

Las grandes áreas urbanas y, en especial, las áreas metropolitanas poseen en general características geográficas propias, fundamentalmente basadas en la interdependencia y en la dimensión de las actividades, factores y problemas que se desarrollan en ese lugar, siendo la complementariedad una de las ideas características de estos espacios.

La cuestión que con más insistencia surge a propósito de las áreas metropolitanas es la de saber dónde está situado institucionalmente o cuál es su modelo de gestión. La respuesta a esta cuestión tendrá que conjugar necesariamente varios componentes: los sectores de intervención (que incluyen siempre, por lo menos, la planificación territorial y los transportes)4; los niveles de intervención (que pueden ser de carácter estratégico, de planificación, de programación o de ejecución); la financiación (cuestión íntimamente ligada a la anterior, ya que si la intervención fuese más estratégica 0 planificada, los recursos financieros tenderían a ser menores, mientras que si la intervención fuera más operativa, la financiación tendería a ser más amplia) y la orgánica 5 .

El modelo de gestión de las áreas metropolitanas es, por tanto, una de las cuestiones fundamentales para quien pretenda estudiar con profundidad este problema.

Veámoslo más atentamente.

\section{Visión general sobreel sistema de «gobernanza» en las áreas metropolitanas en Portugal}

\subsection{Los modelos teóricos posibles 6}

Si pensamos en un modelo de gestión de las áreas metropolitanas, llegaremos a la conclusión de que no existe un solo modelo posible, sino varios.

Los modelos de gestión de las áreas metropolitanas pueden ser divididos en dos grandes grupos. El primero de ellos es el que reúne las soluciones administrativas que institucionalizan un nuevo nivel de administración supramunicipal; el segundo, el que opta por soluciones de gestión intermunicipal.

En lo que respecta al primer grupo es posible extraer cuatro soluciones distintas. Veamos resumidamente en qué consiste cada una de ellas.

\section{i) La autarquía* regional (Región)}

La creación de una autonomía regional como respuesta a los problemas que surgen en las áreas metropolitanas es un modelo posible en cuanto a su organización, ahora bien, la naturaleza jurídica reconocida a la referida región puede variar según se trate de una región político-administrativa - en la que entre sus atribuciones pueden existir la capacidad legislativa- , 0 una región meramente administrativa - en la que los poderes funcionales se limitan a poderes autónomos de índole deliberativa-ejecutiva, sin incluir la producción legislativa en el territorio respectivo-.

\section{ii) Redes de cooperación intermunicipal}

La necesidad de gestión integrada en las grandes áreas urbanas puede llevar también a la aparición de formas de cooperación intermunicipal. Ésta puede asumir, por tanto, diversos niveles, desde la creación de simples órganos de concertación de políticas municipales con carácter meramente consultivo, hasta entidades más sofisticadas con estructuras permanentes y financiación específica. La cooperación intermunicipal puede ser además más o menos obligatoria para todos los municipios que integran el área metropolitana. 
Independientemente del modelo en sí, no hay duda de quela cooperación entre municipios asume una función fundamental en materia de áreas metropolitanas por varios factores: la responsabilidad excesiva del espacio municipal en relación a los servicios que los municipios tienen que desarrollar, que exigen, muchas veces, una implantación más amplia que la de su área; una creciente densidad de población, que reclama un aumento y una mejora de la capacidad de respuesta de los servicios municipales; la escasez de medios financieros y técnicos que lleva a los municipios a asumir esquemas de cooperación con el fin de reducir los costes económicos de los servicios prestados a través del reparto de las necesidades de un servicio por varios municipios, etc. ${ }^{\text {. }}$.

\section{iii) Entes de estructura estatal o desconcentrada del Estado}

Este modelo determina la creación de una institución que depende o se asocia, de modo directo 0 indirecto, al propio Estado, y que asume el papel de coordinación metropolitana y gestión en varios campos de intervención previamente definidos.

\section{iv) Entes de estructura mixta}

0 tro modelo posible de organización y gestión de las áreas metropolitanas es el que lleva a la institucionalización de un ente que asocia entidades diversas, establecido por representantes de los municipios y de organismos desconcentrados del Estado.

Al lado del modelo que institucionaliza un nuevo nivel de administración supramunicipal, existen soluciones que optan por una gestión intermunicipal, más o menos sectorial, que puede tomar la forma de estructuras supramunicipales de adhesión voluntaria para alcanzar fines específicos en ciertos campos (i); la constitución de administraciones autónomas para determinados sectores de intervención municipal (ii); o la constitución de empresas públicas de capital municipal o mixto (municipio y Estado, o entidades públicas y privadas) (iii).

Podemos resumir los varios modelos posibles de gestión de las áreas metropolitanas en el siguiente cuadro de síntesis (C uadro 1).

Las soluciones a adoptar cuando la organización o el gobierno de las áreas metropolitanas está por hacerse 0 deshacerse en todo el mundo, hace que permanezca abierta la cuestión sobre el mejor modelo para hacerlo y hace posible también que puedan surgir nuevas propuestas8. Siendo así, a efectos de esta pequeña incursión, es más importante que la discusión de los modelos abstractos posibles, el señalar cómo se ha desarrollado esta discusión en Portugal.

\begin{tabular}{|c|c|}
\hline \multicolumn{2}{|c|}{ Cuadro 1} \\
\hline $\begin{array}{c}\text { Nuevo nivel de administración } \\
\text { supramunicipal }\end{array}$ & \multicolumn{1}{|c|}{ Gestión intermunicipal } \\
\hline - La autarquía regional (Región). & $\begin{array}{l}\text { - Estructuras supramunicipales de } \\
\text { adhesión voluntaria para } \\
\text { alcanzar fines específicos en } \\
\text { campos específicos. } \\
\text { - Entes de cooperación } \\
\text { intermunicipal }\end{array}$ \\
$\begin{array}{c}\text { Constitución de } \\
\text { administraciones autónomas } \\
\text { para determinados sectores de } \\
\text { intervención municipal. } \\
\text { - Entes de estructura estatal } 0 \\
\text { desconcentrada del Estado } \\
\text { - Entes de estructura mixta. }\end{array}$ & $\begin{array}{l}\text { Empresas públicas de capital } \\
\text { municipal o mixto. }\end{array}$ \\
\hline
\end{tabular}

\subsection{Los modelos discutidos en Portugal}

También en Portugal la formación, desarrollo y rejuvenecimiento, junto a las grandes ciudades, de centros de población adyacentes a ellas, fomentó una unidad e intimidad entre la ciudad y sus respectivos al rededores, originando una población común con problemas que pueden encontrar soluciones también comunes9. La problemática de las áreas metropolitanas no dejó, por eso, de surgir también entre nosotros, teniendo en cuenta que también aquí se hace sentir la necesidad de promover una gestión especial de los servicios cuyo ámbito excediese las fronteras municipales, dejando apenas para el ámbito de las atribuciones específicas de cada municipio aquellos servicios que no exigen inequívocamente una gestión integrada.

En Portugal, el problema de organización de las grandes ciudades/áreas metropolitanas surgió primero en la ciudad de Lisboa y más tarde en la de 0 porto. Son éstas, hasta este momento, las dos únicas grandes ciudades donde, en Portugal, surgieron problemas específicos hasta el punto de merecer un tratamiento (legislativo) especial, como tendremos oportunidad de comprobar. D urante mucho tiempo las demás ciudades portuguesas fueron consideradas ciudades pequeñas o medianas, pero ahora se realizan ensayos para definir otras grandes áreas urbanas (igual que las de Lisboa y 0 porto) que justifiquen 0 aconsejen modelos de gestión alternativos, asignando modelos de gestión supramunicipal10. El estancamiento del crecimiento de las áreas metropolitanas y el ritmo de crecimiento acelerado de algunos centros de tamaño medio superior a la media nacional justifican la importancia que cada vez más se está dando a otras áreas urbanas que no sean Lisboa y 0 porto, estando este fenómeno en el origen de al gunos estudios y trabajos de investigación que inten- 
tan identificar cuáles son las ciudades o grupos de ciudades que pueden merecer la calificación de grandes áreas urbanas ${ }^{11}$.

En lo que se refiere a las grandes áreas urbanas no metropolitanas se conoce un movimiento asociativo intermunicipal parala resolución de problemas comunes. A falta de institucionalización de una forma propia de gobierno o de organización administrativa en estos espacios, la asociación de municipios ha sido la figura utilizada para la gestión concertada, en una lógica de cooperación integrada. Si esta actitud revela un intento de integración territorial, la dificultad sentida por los actores en la definición de los contornos de una estructura de gestión y el hecho de pérdida de poderes efectivos de los municipios demuestra la incipiente práctica/cultura de cooperación/coordinación horizontal, asentada en iniciativas puntuales 0 en torno a cuestiones muy específicas12.

Respecto a las áreas metropolitanas de Lisboa y 0 porto, la solución por la que se optó en Portugal fue la institución de una asociación especial (obligatoria) de municipios, sistema que se caracteriza por la aprobación de una ley que establece la asociación del municipio de la gran ciudad con los municipios limítrofes sin que ninguno de ellos pierda su respectiva autonomía, habiéndose instituido, así, un régimen de cooperación para la resolución de sus problemas comunes. Esta opción ha tenido subyacente la necesidad de sal vaguardar la identidad de los municipios que, en su mayoría, tienen un tamaño apreciable; entendiéndose que para que se alcanzase la asociación sería necesario buscar soluciones que los «aligerasen», como podía ser la creación de un nivel político supramunicipal (a elegir directamente), bien fuese el subregional, bien haciéndolo coincidir con la aglomeración de una Región Administrativa. El adelgazamiento municipal al que se alude podía resultar, 0 de un nuevo nivel político-administrativo metropolitano que sustituyera a los municipios en al gunas de las competencias que, mejor o peor, vienen desempeñando 0 que les pudieran ser conferidas, o también, por tener competencias que al sobreponerse a las de los municipios, pudieran provocar conflictos entre los dos niveles autónomos13.

Ahora bien, la cuestión que a este propósito se plantea es saber si ésta ha sido, de hecho, la mejor solución para el problema que se intentaba resolver. En cualquier caso, al lado de esta solución, se discutieron otras dos como alternativas. La primera de ellas sería la opción por el sistema de anexión de los pequeños municipios suburbanos por el municipio de la gran ciudad, sistema que se caracterizaría por la absorción en su interior de los municipios que hasta ahora eran sólo vecinos'14.

La segunda solución posible correspondería al sistema de creación de una autonomía supramunicipal, sistema que se caracterizaría por el hecho de mantenerse las autonomías municipales existentes en el área metropolitana, creándose paral elamente una nueva autonomía de nivel superior, la cuál englobaría (y sustituiría) a ciertos efectos - pero no para todos- a la gran ciudad y los municipios de sus al rededores.

La opción por el sistema de asociación especial (obligatoria) demunicipios no dejó de suscitar dudas acerca de la sanción en la Constitución de la República Portuguesa de una norma que apuntaba hacia una solución del último tipo indicado. En efecto, aún hoy el n- 3 del art. 2360 de la Constitución determina que:

«En las grandes áreas urbanas (...) la ley podrá establecer, de acuerdo con sus condiciones específicas, otras formas de organización territorial autónoma» (la cursiva es nuestra).

Apunta, así, nuestra Constitución por la institución de una nueva autonomía de carácter supramunicipal, al lado de las ya existentes parroquias y municipios, donde aún no exista región administrativa.

Pese a esta previsión constitucional, la verdad es que la solución adoptada en Portugal en 1991, año de publicación del Decreto-Ley n-44/91 que instituye las Áreas M etropolitanas de Lisboa y 0 porto, no fue la de constitución de una autonomía supramunicipal. Falta como veremos, en las áreas metropolitanas, para ser autonomías locales, la elección directa por el respectivo electorado de sus órganos dirigentes. Ahora, «sin existir, por lo menos, una «asamblea elegida por sufragio universal, directo y se creto de los ciudadanos residentes) (CRP, art. $241 \underline{0}, n .-2$ ), no hay autonomía local»15.

La opción por una solución como la que fue adoptada es de fendida y justificada en la actualidad por varios autores, en el sentido de que ésta era la única opción que no toleraría la posibilidad de que el área metropolitana formase parte de una Re gión Administrativa amplia. Efectivamente, estando abierto, durante muchos años, el debate sobre la creación de las regiones administrativas, y no sabiendo concretamente cuál es el futuro de las áreas metropolitanas en el ámbito de las mismas, se optó por una solución que fuese suficientemente flexible para que se pudiese adaptar de forma adecuada al futuro modelo regional que el país fuese a consagrar16.

Teniendo en cuenta que la vía de la regionalización se encuentra abandonada, ya que la consulta directa de carácter nacional relativa a cada área regional, realizada el día 8 de noviembre de 1998 por exigencia del artículo 256 no 1 de la Constitución de la Republica Portuguesa, no obtuvo el voto favorable expreso de la mayoría de los electores que se pronunciaron, muchos entienden que ha llegado el momento de reflexionar si el modelo asociativo está, efectivamente, preparado para la resolución de los problemas específicos de las grandes áreas metropolitanas.

Argumentos como el de la disminución de la legitimidad de mocrática y de una cierta distancia de los órganos a la población, fruto de la inexistencia de un órgano representativo elegido por 
sufragio directo, han sido señalados para justificar la necesidad de optar por una solución de organización autónoma. Después de eso, se entiende que el establecimiento de una autonomía metropolitana, elegida por la población «facilitaría la devolución al nivel metropolitano de funciones que, en ausencia de este nivel, serían responsabilidad de la administración central. Esta materialización del principio de subsidiariedad administrativa reforzaría, obviamente, la democratización de las decisi ones que afectasen al área metropolitana» ${ }^{17}$. Se comprueba, pues, actualmente, cada vez más, que el modelo asociativo no está preparado para la resolución de los conflictos de intereses y de los problemas comunes de las grandes áreas urbanas, especialmente la ordenación del territorio, el urbanismo, los transportes públicos, la captación y distribución de agua, el saneamiento básico, el tratamiento de residuos sólidos, los aeropuertos, puertos, hospitales, etc... , que exceden en mucho las competencias exclusivas de los diferentes municipios ${ }^{18}$.

Pese a la actualidad de esta discusión, lo cierto es que el modelo de organización de las áreas metropolitanas en Portugal es hoy el de la Ley $n-44 / 91$, de 2 de agosto, que creó, en el ordenamiento jurídico portugués, las Áreas M etropolitanas de Lisboa y 0 porto. Se entiende que la opción por la institución del área metropolitana, no como una autonomía, sino como una asociación (si bien especial) de municipios era la que mejor respondía a la necesidad de garantizar el mantenimiento de un conjunto de atribuciones como estrictamente municipales, aunque pudiesen ahora ser desarrolladas en cooperación o conjunción de esfuerzos con otros municipios'19. Habiendo sido (y siendo hasta hoy) ésta la opción que, en términos organizativos, hacemos en cuanto al «sistema de gobierno» para las áreas metropolitanas, veamos cuales son los principales trazos característicos de su régimen en la referida Ley $\mathrm{n}-44 / 91$.

\subsection{El modelo actualmente vigente}

El legislador portugués establece en 1991, con la Ley no 44/91, una asociación de municipios de carácter imperativo que une a las dos grandes ciudades - Lisboa y 0 porto- con sus respectivos municipios limítrofes. El Área M etropolitana de Lisboa tiene su sede en Lisboa y comprende 18 municipios: Alcochete, Almada, Amadora, Azambuja, Barreiro, Cascais, Lisboa, Loures, M afra, M oita, M ontijo, 0 eiras, Palmela, Sesimbra, Setúbal, Seixal, Sintra e Vila Franca de Xira (artículo 2ㅇ, n.ำ 1)20. El Área M etropolitana de 0 porto tiene su sede en 0 porto y comprende 9 municipios: Espinho, Gondomar, M aia, M atosinhos, Porto, Póvoa do Varzim, Valongo, Vila do Conde e Vila N ova de Gaia

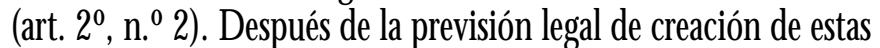
dos áreas metropolitanas, su formación en concreto depende del voto favorable de la mayoría de dos tercios de las asambleas mu- nicipales que represente a la mayoría de la población del área respectiva.

En términos del no 2 del artículo 10 de la Ley n- 44/91, las áreas metropolitanas son definidas como personas colectivas públicas de ámbito territorial, que buscan la satisfacción de intereses propios de las poblaciones del área de los municipios integrantes y que tiene, por eso, atribuciones fundamentalmente relacionadas con los transportes colectivos y las vías de comunicación, saneamiento básico, abastecimiento público, ambiente y recursos naturales, protección civil e inversiones de ámbito supramunicipal (cfr. artículo 40). № estamos, por tanto, propiamente en el ámbito de atribuciones propias y específicas del Area M etropolitana, ya que la mayor parte de las atribuciones referidas son propias y específicas de cada uno de los municipios, cabiendo al Area M etropolitana una tarea más limitada de articulación de la actuación de cada uno de ellos en estas áreas21.

Basta, en efecto, hacer una lectura atenta de alguna de las varias líneas del no 1 del artículo 4 de la Ley 44/91 para llegar a esta conclusión. Veamos:

Artículo $4^{-}$ ciones:

«1. Las áreas metropolitanas tienen las siguientes atribu-

a) Asegurar la articulación de las inversiones municipales que tengan ámbito supramunicipal.

b) Asegurar la conveniente articulación de los servicios de ámbito supramunicipal, fundamentalmente en el sector de los transportes colectivos, urbanos y suburbanos y de las vías de comunicación de ámbito metropolitano.

c) Asegurar la articulación de la actividad de los municipios y del Estado en los ámbitos de las infraestructuras, del saneamiento básico, del abastecimiento público, de la protección del ambiente y los recursos naturales, de los espacios verdes y de la protección civil.

$$
\text { (....)» }
$$

Citar que las áreas metropolitanas, a pesar de tener un patrimonio y finanzas propias (artículo 5, n- 1), viven, sobre todo, de las transferencias que reciban del Presupuesto $G$ eneral del Estado y de los presupuestos municipales (artículo 5, no 3), no teniendo, además, capacidad tributaria. Este es, de hecho, uno de los puntos débiles del sistema portugués. D e hecho, los actuales recursos de las áreas metropolitanas son escasos, sobre todo comparados con los de los municipios, fenómeno que se considera como el principal responsable de un nivel débil de intervención de estas entidades: la ausencia de medios financieros de las Áreas M etropolitanas disminuye su capacidad de poder desarrollar cualquier orientación. 
El área metropolitana tiene como órganos propios la asamblea metropolitana (órgano deliberativo) y la junta metropolitana (órgano ejecutivo), y además una comisión permanente para los asuntos corrientes. El primero está constituido por miembros elegidos por las asambleas municipales de los municipios comprendidos (50 en Lisboa y 27 en 0 porto) - artículo 9, no 1- , y el segundo está constituido, por inercia, por los presidentes de las cámaras municipales de los municipios participantes (18 en Lisboa y 9 en 0 porto), que, de entre ellos, eligen un presidentey 402 vicepresidentes, respectivamente, en Lisboa y en 0 porto (artículo 130). La comisión permanente está formada por el presidente y los vicepresidentes de la junta (artículo 14²).

La ley prevé también la existencia de un consejo metropolitano, órgano de carácter consultivo, compuesto por el presidente de la Comisión de Coordinación Regional respectiva22, por los miembros de la junta metropolitana y por los representantes de los servicios y de los organismos públicos cuya acción interfiera en las atribuciones del área metropolitana23. En este consejo pueden también participar, aunque sin derecho de voto, representantes de los intereses sociales, económicos y culturales. Se trata, como veremos, de un verdadero órgano de cooperación.

\section{4. Área metropolitana de O porto y Área metropolitana de Lisboa: comparación de sus características}

La reflexión sobre la situación portuguesa implica detenernos sobre las características de nuestras dos Á reas M etropolitanas que son, de hecho, muy diferentes, y no sólo por el hecho de que una de ellas sea la capital del país.

El Área M etropolitana de Lisboa es anterior a la de 0 porto, habiendo registrado un crecimiento espectacular en las décadas de los 60/70, pero dando al gunas señales de desaceleración en las décadas siguientes. Por el contrario, el Área M etropolitana de 0 porto, que tuvo en las dos primeras décadas referidas un crecimiento más moderado que la de Lisboa, mantuvo posteriormente un crecimiento más vivo, sin dar síntomas de debilitamiento. A pesar de la distinta evolución del crecimiento, es verdad que aún hoy el Área M etropolitana de 0 porto representa menos de la mitad del área que abarca el Área M etropolitana de Lisboa, re sidiendo en ella 1,3 millones de habitantes mientras que en esta última habitan 2,8 millones.

La estructura de las Áreas M etropolitanas es también distinta: el Área M etropolitana de Lisboa es monocéntrica, teniendo la ciudad de Lisboa un peso abrumador sobre ella, siendo un área más concentrada que la de 0 porto. En cambio, el Área M etropolitana de 0 porto es más equilibrada, policéntrica (Gaia se aproxima rápidamente al nivel de población de 0 porto; $M$ atosinhos tiene un fuerte papel económico e industrial). Tiene ade- más fronteras mal definidas (posee niveles de crecimiento urbano rápidos, tanto hacia el sur, como hacia el norte).

Además de estos aspectos, las Áreas M etropolitanas de Lisboa y 0 porto se distinguen también por los diferentes tipos de estructura geográfica, actividades productivas y vivienda. En efecto, el Área M etropolitana de Lisboa se caracteriza por la concentración de servicios en el municipio central, y la concentración de viviendas en la periferia, en cambio, en el área de 0 porto existe una dispersión industrial y un modelo de vivienda periurbano que se expande sin solución de continuidad hacia otras áreas donde ya no tiene sentido hablar de relación metropolitana.

A su vez, el transporte regular y los desplazamientos presentan problemas muy diferentes en una y otra área, aumentándose también por el hecho de que los municipios periféricos de O porto no presentan el «grado de dormitorio» que el de los que rodean Lisboa.

A pesar de estas y otras diferencias fundamentales entre nuestras dos Áreas M etropolitanas, podemos encontrar algunos puntos comunes. En ambas el tamaño de los municipios periféricos del primer círculo es importante, situándose entre los mayores del país. Por otro lado, tanto en el Área M etropolitana de Lisboa como en la de 0 porto los municipios centrales no disponen ya de grandes áreas urbanizables, ni siquiera podrían mejorar significativamente la accesibilidad de sus zonas centrales; en cambio, los municipios periféricos tienen mayores disponibilidades para funciones urbanas, incluida la industria. Todo esto lleva a que los municipios tienden a estar más preparados para funciones de gestión, no aceptando, por cierto, con buenos ojos la posibilidad de perder atribuciones por transferencia hacia órganos de gestión supramunicipales o los mismos intermunicipales, a no ser en ámbitos muy especializados o técnicos (o con escasa incidencia política) 24.

\section{Las relaciones entre los distintos niveles de poder territorial}

La ley portuguesa es negligente en cuanto a la forma de relación (y el correspondiente vínculo) de la entidad metropolitana con las autonomías locales, por un lado, y con el gobierno central, por otro.

En las relaciones con el gobierno central, la institución metropolitana funciona casi siempre como grupo de presión y muy poco como parte con poder efectivo en las negociaciones de de 
terminados objetivos. El «gobierno» metropolitano raramente es oído en los asuntos importantes y relevantes.

Internamente, las decisiones tomadas en la instancia metropolitana no son vinculantes para los municipios, siendo aplicadas solamente cuando reporten beneficios para el nivel local25.

Éste es precisamente uno de los aspectos negativos del modelo de gestión de las áreas metropolitanas actualmente vigente en Portugal, ya que incentiva una desresponsabilización del gobierno central y genera dificultades en la aplicación de las orientaciones metropolitanas por parte de los municipios. En la relación con éstos el gran problema es, como decimos, el grado de vinculación a que están sujetas las autonomías locales que integran el área metropolitana después de las deliberaciones de la junta y la asamblea metropolitanas: ipueden los municipios no respetar las orientaciones metropolitanas? ¿Cómo se hace la delimitación de competencias entre los municipios y la respectiva área metropolitana? A estas cuestiones, el modelo actual no ha sabido dar respuestas satisfactorias, lo que justifica, precisamente, la más que probable necesidad de su reformulación.

Se hace, pues, necesario garantizar un estatuto reforzado a la autoridad metropolitana, dándole poderes capaces de vincular simultáneamente a las autonomías y a la administración central, eliminar conflictos entre las políticas sectoriales, conducir investigaciones y debates sobre problemas actuales y futuros y formalizar estrategias a escala metropolitana26. Es en esta escala en la que deben colocarse los numerosos problemas que carecen de una visión conjunta, prospectiva, que permita el diseño y la implementación de políticas y proyectos de ordenación.

La matriz de desarrollo de la gran metrópoli no puede resultar de la intervención de cada uno de los diversos niveles territoriales considerados de forma aislada, exigiendo, por el contrario, la conjunción de las acciones de cada una de ellas. Se hace, pues, fundamental establecer un modelo que deje muy claro cuál es el tipo de relación a establecer entre el área metropolitana con el nivel de poder territorial superior - el Estado- y con el nivel de poder territorial inferior - los municipios- Y Y la regulación de estas relaciones debe ser claramente delimitada debiendo, independiente mente del model o que se diseñe, basarlo en una idea de concertación entre los municipios y el Estado en la lucha con los problemas estructurales que en tantos ámbitos afectan a la calidad de vida y al bienestar de la población, y de cooperación y conjunción entre varios municipios sin perjudicar a su autonomía.

Al revés de esta delimitación clara del tipo de relación a establecer entre los varios niveles de poder territorial, la Ley n44/91 regula esta materia de una forma muy insuficiente. En efecto, esta ley apenas prevé la existencia del consejo metropolitano a quien compete, en términos del artículo 20, la concertación y la coordinación entre los diferentes niveles de la Administración - los municipios que integran el área metropolitana y el Esta- do- , órgano donde tiene asiento el presidente de la Comisión de Coordinación Regional respectiva, representantes de los municipios, miembros de la junta metropolitana y de varias instancias de la administración directa o indirecta que ejerzan su actividad en el respectivo ámbito territorial.

Se trata, por tanto, de una solución nítidamente incipiente para garantizar la coordinación y concertación entre los varios niveles de poder territorial implicados, no permitiendo alcanzar los niveles de eficacia y eficiencia pretendidos y exigidos.

En lo que atañe a las relaciones entre las Áreas M etropolitanas y el Estado, aunque aquellas no sean verdaderas autonomías (supramunicipales), la verdad es que el legislador las incluye en cierta medida, a este efecto, en el mismo ámbito que a la llamada administración autónoma, lo que tiene como consecuencia sujetarlas a la relación de control típico que el Estado ejerce relativamente en esta modalidad de administración: la tutela ${ }^{29}$. En efecto, la actual ley de tutela administrativa (Ley n-27/96 de 1 de agosto), al definir su ámbito de aplicación, determina en su artículo 1ํ, que:

\section{Artículo 10}

«1. La presente Ley establece el regimen jurídico de la tutela a la que están sujetas las autonomías locales y entidades equiparadas, como el respectivo régimen sancionador.

2. A efectos del presente título son consideradas entidades equiparadas a las autonomías locales las áreas metropolitanas, las asambleas de distritos y las asociaciones de municipios de derecho público» (la cursiva es nuestra).

La tutela del Estado aquí considerada consiste en un conjunto de poderes que éste tiene para intervenir en la gestión de otra persona colectiva pública - en este caso, el área metropolitana- , a fin de asegurar la legalidad de su actuación. D e esta definición resulta que la tutela que aquí está en juego tiene por fin asegurar, en nombre del Gobierno, que el área metropolitana cumpla las leyes en vigor28.

La tutela que el Estado ejerce sobre las áreas metropolitanas abarca, en cuanto al contenido, la tutela inspectora (poder de fiscalizar la organización, el funcionamiento de los órganos o servicios, los documentos y las cuentas de la entidad tutelada); la tutela inte gradora (poder de aprobar 0 autorizar los actos de la entidad tutelada); y la tutela anulativa (poder de anular los actos administrativos practicados por la entidad tutelada). No se admite, por el contrario, la tutela revocatoria (poder de revocar, por motivos de oportunidad, los actos administrativos practicados por la entidad tutelada), la tutela sancionadora (poder de aplicar sanciones por irregularidades que hayan sido detectadas por la entidad tutelante), y la tutela susitutiva (poder de suplir las omisiones de las entidades tuteladas, realizando en vez de ellas y por cuenta de ellas, los actos que hubiesen de ser legalmente realizados) 29. 


\section{Los grandes desafíos de las A reas M etropolitanas: los ámbitos de intervención privilegiados}

Una vez analizado el sistema vigente en Portugal respecto a la gestión de las áreas metropolitanas, pensamos que los resultados obtenidos nos permiten señalar que ha llegado el momento de replantearse, y eventualmente poner en marcha, nuevos instrumentos de gestión para las aglomeraciones urbanas en Portugal. Estamos, en efecto, actualmente, en una fase en que, tal como ocurre en otros países europeos, se replantea la organización económico-social y administrativa, y también política- de estas ciudades-región.

Constituye un grupo cada vez más complejo de nuevos problemas, cuestionándose crecientemente si la simple buena voluntad asociativa y de negociación de la que han dado pruebas diversos grupos de municipios no tiene un alcance demasiado limitado. La vía asociativa ha valido, es cierto, cuando la realización del interés común ha sido compatible con el interés a corto plazo de cada partícipe autónomo, pero difícilmente esas agrupaciones tienen legitimidad para redistribuir o gestionar oportunidades que constituyan discriminaciones positivas para la cohesión del sistema en su conjunto.

A la vez que esta cuestión, se comprueba que el sistema urbano en Portugal camina a grandes pasos hacia una bipolarización Área M etropolitana de Lisboa versus Área Metropolitana de 0 porto, igual que hacia una «homogeneización» del Área Metropolitana de Lisboa. Ahora, es fundamental destacar que le sale caro al país el abandono del interior, pero le sale aún más caro la sobrecarga de las áreas metropolitanas. Efectivamente, los costes de la metropolización no son ya inferiores a los costes de la interioridad. En esta lógica, se ha defendido la necesidad de dar prioridad al equilibrio del sistema urbano nacional y a la organización y cualificación de las áreas metropolitanas, y no al refuerzo de su dimensión como factor de competitividad de los países y las regiones30.

Pensamos que la actuación de las áreas metropolitanas debe estar reservada sólo para todas las tareas y políticas para cuya realización se encuentran particularmente bien preparadas, dejando las restantes para el nivel territorial (estatal o municipal) adecuado para ello.

En esta lógica, pensamos que existen un conjunto de políticas que deben ser atribuidas fundamentalmente a las áreas metropolitanas, siendo como grandes desafíos a los que éstas debe- rán enfrentarse en los próximos tiempos. Veamos qué políticas son esas:

\section{Ordenación del territorio y planificación territorial}

La ordenación del territorio es, definitivamente, uno de los ámbitos en los cuales las áreas metropolitanas se encuentran particularmente bien preparadas para responder. Varias son las tareas que en este ámbito recaen sobre los órganos propios de las áreas metropolitanas, pero sólo haremos referencia a algunas de ellas.

\subsection{El acompañamiento en la elaboración de los planes de ordenación del territorio con incidencia en el área metropolitana}

Respecto a la materia de planificación territorial en el ámbito de ordenación del territorio, la tarea de las áreas metropolitanas se encuentra particularmente limitada. En primer lugar, en el punto d) del no 1 del artículo 4 sele atribuye, en este ámbito, las simples funciones de acompañar la elaboración o la ejecución de los planes de ordenación del territorio en el ámbito municipal o me tropolitano (planes municipales - planes directores municipales, planes de urbanización y planes de detalle- , o planes estatales con aplicación en el área).

Se trata, no obstante, desde la perspectiva de la ley que actualmente regula esta materia (D ecreto-Ley $n-380 / 99$ del 22 de septiembre), de una tarea de gran relieve. En efecto, teniendo en cuenta la forma en que se encuentra actualmente diseñado el procedimiento de elaboración de los instrumentos de planificación, creemos que apunta claramente a la coordinación de las entidades incluidas. La coordinación de operaciones en este ámbito se materializa en el hecho de que la entidad responsable de cada uno de estos instrumentos (el municipio, en el caso de los planes municipales y el Estado en el caso de los planes de su competencia) no actúa sola en su elaboración, sino con la compañía de varias entidades; designando dos representantes, con especial relieve, de los intereses a proteger o que puedan ser perjudicados del área territorial correspondiente que se encuentre dentro del área metropolitana, entidades éstas que componen un órgano administrativo ad hoc de acompañamiento en la elaboración del plan, que se llama comisión mixta de coordinación.

Este órgano de coordinación está obligado a participar fre cuente y continuadamente en los trabajos de elaboración de los futuros planes debiendo, al final, presentar una declaración escrita, firmada por todos los miembros, con mención expresa de la orientación defendida, pudiendo aśí pronunciarse, en el ámbito de elaboración de algunos planes, sobre la adecuación 0 
conveniencia de las soluciones propuestas. La opinión de la comisión mixta de coordinación expresa el análisis realizado por las diversas entidades representadas, teniendo lugar una posterior audiencia de aquellas que formal mente hayan discrepado de las orientaciones definidas en el futuro plan. En efecto, concluida la elaboración del plan, la entidad responsable remite su propuesta, acompañada del informe emitido por el órgano de coordinación, para que opinen las entidades que hayan discre pado formalmente de las soluciones definidas en el futuro plan, debiendo las opiniones de estas entidades señalar las razones de su discrepancia al proyecto de plan.

Recibidas las opiniones, la entidad responsable de la elaboración de los planes (municipio o Estado) tendrá que impulsar la realización de reuniones con las entidades que los hayan emitido con vista a obtener una solución concertada que permita superar las objeciones formuladas.

Se trata, explícitamente, de una nueva actitud que exigimos a la Administración en materia de planificación, en la medida en que las entidades constituidas para acompañar la elaboración de los planes pasen a tener una mayor responsabilidad, ya que el resultado final de este proceso se traduce en la consagración de soluciones concertadas entre varias entidades con funciones e intereses relevantes en la materia31. Esto significa que la mera tarea de acompañamiento, por parte de los órganos metropolitanos, a los planes de ordenación del territorio aplicados en el área tienen una relevancia importante en la medida en que, en el caso de que no concuerden con las soluciones proyectadas, podrán siempre emitir una opinión desfavorable, abriendo así una fase de concertación/negociación con la entidad responsable de la elaboración del plan buscando alcanzar una solución consensuada. Esto significa que el acompañamiento que las áreas metropolitanas hacen en la elaboración de los planes de ordenación del territorio aplicables en el área se traduce, actualmente, en el contexto de la nueva legislación en la materia, en una actitud activa y no de mero oyente por las entidades competentes de la planificación, traduciéndose en un poder de influencia en el contenido de aquellos instrumentos de ordenación.

\subsection{La elaboración deinstrumentos de planificación territorial por el área metropolitana 32}

En materia de planificación espacial, la intervención de las áreas metropolitanas se debe traducir no sólo en acompañar la elaboración de los planes de competencia de los otros niveles de administración, sino también en la elaboración de sus propios planes. En efecto, la Ley de Bases de Política de 0 rdenación del Territorio y de U rbanismo (Ley n- 48/98, de 11 de agosto) y el Decreto-Ley $n-380 / 99$, de 22 de septiembre (que instituyó el régimen juridico de los instrumentos de gestión territorial, en desarrollo de la Ley de Bases) prevén la elaboración de los llamados planes intermunicipales de ordenación del territorio, definiéndolos como instrumentos de desarrollo territorial 33 que aseguran la articulación entre el plan regional y los planes municipales de ordenación del territorio, en el caso de las áreas territoriales que, por la interdependencia de sus elementos estructurantes, necesiten de una coordinación integrada - artículo 600, n- 1- . La elaboración de estos planes intermunicipales y la responsabilidad de los municipios asociados para ello o de las asociaciones de municipios, estable ciendo las opciones propias de desarrollo estratégico y dando el visto bueno a la articulación estratégica entre áreas territoriales (de ámbito municipal) se refleja en el artículo 9-, n- 1, punto c) de la Ley de Bases.

Teniendo en cuenta la vocación intermunicipal de estos planes, estamos ante un instrumento de planificación con una enorme potencialidad de aplicación en el ámbito específico de las áreas metropolitanas, aunque ahora tenga carácter discrecional. M ientras tanto, para que estos planes puedan ser elaborados por los respectivos órganos metropolitanos, tiene que hacerse un ajuste legislativo en lo referente a la competencia para su elaboración, una vez que, aunque se prevé que estos planes sean elaborados por asociaciones de municipios, la ley se refiere sólo expresamente a asociaciones voluntarias y no a las obligatorias, como es el caso de las áreas metropolitanas (la ley se refiere sólo a la aprobación por las asambleas municipales respectivas o por las asambleas intermunicipales, no dice nada sobre las asambleas metropolitanas).

Prueba de la enorme potencialidad de los planes intermunicipales relativos a las áreas metropolitanas es el hecho de que éstas tienen como objetivo articular estrategias de desarrollo económico y social de los municipios incluidos, de modo especial a nivel de estrategia intermunicipal de protección de la natural eza y de garantía de la calidad ambiental, el establecimiento de objetivos de racionalización de la población a medio y largo plazo, la definición de objetivos en materia de acceso a equipamientos y servicios públicos y la coordinación de la incidencia intermunicipal de los proyectos de redes, equipamientos, infraestructuras y distribución de las actividades industriales, turísticas, comerciales, y de servidores constantes del programa nacional de política de ordenación del territorio, de los planes regionales de ordenación del territorio y de los planes sectoriales aplicables - artículo 610 del Decreto-Ley $n^{0}$ 380/99.

Además de esta cuestión, los planes intermunicipales establecen las directrices para el uso integrado del territorio abarcado, definiendo las redes intermunicipales de infraestructuras, equipamientos, transportes y servicios y los patrones mínimos a emplear en materia ambiental (artículo 620)34. 
Algunos ajustes legislativos permitirían, pues, la utilización de los planes intermunicipales de ordenación del territorio por las áreas metropolitanas, aspecto éste, que teniendo en cuenta los objetivos de este tipo de plan, se convierte, para nosotros, en indispensable.

1.3. Un ejemplo de planificación territorial en área metropolitana: el Plan Regional de Ordenación del Territorio del Área M etropolitana de Lisboa

La Comisión de Coordinación Regional de Lisboa y del Valle del Tajo presentó en 1999 el proyecto del Plan Regional de O rdenación del Territorio del Área M etropolitana de Lisboa (PROTAM L) que, acorde con las exigencias de la Ley de Bases de la Política de 0 rdenación del Territorio y de Urbanismo y de su reglamento, tiene una natural eza meramente estratégica35. EI PROTAM L pretende establecer un cuadro estratégico que sostenga las opciones de desarrollo regional y proceder a su especialización; orientar la planificación municipal (o su revisión), programar las realizaciones y cuantificar los medios necesarios para su ejecución, destinándoles fuentes y agentes.

Propone este plan, también, una estrategia de desarrollo para el Área M etropolitana de Lisboa, de forma articulada con el Plan de Desarrollo Social y Económico, estableciendo un modelo territorial, identificando los principales sistemas, redes y articulaciones a nivel regional, proporcionando un plan programático que explicite las acciones de la Administración y oriente la planificación municipal, pero no configura derechos y deberes que permitan la iniciativa de los particulares. Al contrario, responsabiliza a éstos y a la Administración Local de las inversiones de la Administración Central, reflejándolo en un plan de estructura territorial apoyado en una estrategia operativa para su ejecución36.

Aunque se trata de un plan con clara incidencia en el Área M etropolitana, la verdad es que en su elaboración participa (como ocurre con los planes regionales de ordenación del territorio) la Comisión de Coordinación Regional competente en el área, organismo desconcentrado de la Administración estatal. N os parece, sin embargo, esencial, que la gestión de las opciones establecidas en este instrumento de planificación esté esencialmente en manos de la autoridad metropolitana que tiene reducidas pero sólidas atribuciones en materia de ordenación del territorio.

\section{Otros sectores privilegiados de intervención}

D espués de la planificación/ordenación del territorio, el área metropolitana es el nivel adecuado para la gestión ambiental, principalmente la gestión del sector del agua, de los residuos sólidos y también de la planificación y gestión del turismo, la vivienda y los transportes.

\section{Veamos al guno de estos ámbitos.}

\subsection{El sector del turismo 37}

Por lo que se refiere al turismo dos son las cuestiones que normalmente se plantean a este nivel: el de la promoción y el del rendimiento, en primer lugar, y el de la planificación y los servicios, en segundo. La primera función no exige la creación de una autoridad metropolitana, ya que el área metropolitana no es en sí un producto turístico; por tanto, no tiene sentido una entidad para promover ese producto. Respecto a la planificación y a los servicios del sector (hostelería, restauración, animación) es importante que la autoridad metropolitana incluya este ámbito, construyendo una visión estratégica a escala metropolitana y también articulándola con otros factores, principalmente, los transportes. Se justifica así que el área metropolitana tenga alguna intervención en este ámbito.

\subsection{La vivienda}

La Ley que creó las áreas metropolitanas no se refiere expresamente, entre las atribuciones de éstas, a la vivienda, debiendo, no obstante, entenderse que está incluida entre todas las atribuciones referentes a la planificación y a la articulación con la Administración central. La existencia de una estructura metropolitana para la vivienda es defendida por al gunos. Las propuestas más recientes sobre la (re)creación o reforma de las autoridades metropolitanas toman la vivienda como ámbito de competencia propio de la autoridad metropolitana, aunque de importancia secundaria en relación con otros sectores.

El crecimiento desordenado de las grandes áreas urbanas y suburbanas sitúa cuestiones muy particulares en el ámbito de la vivienda. Las características de las áreas metropolitanas, principalmente la búsqueda elevada de suelo urbano y de viviendas, la fuerte presión por construir y la gran movilidad geográfica de la población, introducen especificidades en el mercado de la vivienda que recurre a formas de coordinación estratégica y de programación concertada entre varios municipios38.

Tradicionalmente el problema de la vivienda se centraba en la falta de pisos, justificado muchas veces por la escasez de suelo infraestructurado e insuficiencia de construcción, a nivel global, sobre todo en los lugares más adecuados y a precios competitivos con las condiciones de búsqueda. Hoy en día, 
los problemas van siendo diferentes existiendo un número creciente de pisos vacíos mucho tiempo, que lleva, no a la escasez, sino a una subutilización del parque de viviendas.

En las áreas metropolitanas se identifican factores específicos que afectan al mercado de la vivienda, entre los que se puede destacar la elevada búsqueda de suelo urbano/urbanizable y de viviendas, que lleva a una fuerte presión constructora, a la especulación de los precios, a las construcciones clandestinas (hoy denominadas áreas urbanas de origen ilegal) y a la diferenciación de los espacios por medio de los precios que se traduce en una segregación socio-espacial y en la marginalización de los estratos sociales del mercado normal de vivienda (remitiéndolos al apoyo estatal directo).

La oferta de suelo y de vivienda regida por los principios del mercado exige la intervención concertada en las áreas metropolitanas, pues la lógica en curso en el mercado apuesta por la movilidad geográfica de las personas y por una distancia cada vez mayor casa-empleo y además no tiene en cuenta la perspectiva territorial en la óptica de la sostenibilidad ambiental. La escasez de oferta de suelo y vivienda tiene importancia en municipios específicos. Ahora bien, lo que sucede, como acabamos de explicar, es que el mercado de vivienda es un mercado imperfecto y desequilibrado (pisos no ocupados y falta de conservación del parque existente). Los alojamientos más antiguos y de alquiler, por efecto de la congelación de las rentas y por la falta de una mayor eficacia en las políticas de rehabilitación en este segmento inmobiliario residencial, se encuentran en un estado elevado de degradación pues, en su conjunto, no han merecido la atención privada (más interesadas en operaciones de renovación/sustitución que de rehabilitación/recuperación de los antiguos). Además, en el proceso de sustitución de clases sociales, los espacios de la élite de antaño están siendo terciarizados, pero los nuevos espacios de la élite consumen más recursos y son más segregativos y marginalizantes - v.g., condominios de viviendas cerrados justificando intervenciones públicas diversas, exigiendo mayor coordinación estratégica y una programación concertada entre varios municipios y llamando a una verdadera integración de las políticas de vivienda a nivel supranacional que posibilite actuaciones operativas específicas en estas áreas con características también específicas39-.

Algunos programas han sido aprobados, como es el caso del Programa Especial de Realojamiento en las Áreas M etropolitanas de Lisboa y 0 porto (PER - Autonomías y PERfamilias). El caso de RECRIA (Regimen Especial de Coparticipación y Recuperación de Inmuebles Alquilados), programa de caracter nacional, pero de mayor éxito en las áreas metropolitanas (aunque no haya cubierto las expectativas) y el RECRIH P, reservado a la propiedad horizontal para cubrir las lagunas del RECRIA, son otros ejemplos.
En el caso del A rea M etropolitana de Lisboa, las responsabilidades sobre la vivienda están repartidas entre 19 municipios y la Administración central, la cual actúa a través del Instituto de Gestión y Enajenación del Patrimonio de Vivienda del Estado, del Instituto Nacional de la Vivienda, de la Comisión de Coordinación de la Región de Lisboa y del Valle del Tajo. Los apoyos canalizados para los municipios a través del PER, Intervención 0 perativa de Renovación Urbana, IN TEGRAR, URBAN, entre otros, aumentarían probablemente su eficacia y eficiencia si fuesen coordinadas por una autoridad metropolitana en función de las necesidades y prioridades definidas a partir de la visión de conjunto metropolitano. En la práctica no ha habido coordinación entre los municipios en relación a las propuestas sobre vivienda contenidas en los respectivos PD M : cada municipio actúa como entidad independiente en materia de decisiones sobre vivienda, definiendo las medidas y prioridades en función de sus intereses inmediatos y por encima del interés general del área metropolitana. Algunos trabajos están ya, sin embargo, llevándose a cabo en el ámbito de la vivienda, siendo el caso del PER un buen ejemplo en el que los municipios del Area M etropolitana de Lisboa comienzan a actuar coordinadamente y en conjunto40.

La intervención del área metropolitana en este sector deberá ser sólo estratégica y de coordinación de un conjunto de entidades de diversos sectores, desde la planificación territorial, transporte y medio ambiente hasta el desarrollo económico, entre otros, no debiendo el Área M etropolitana ser una productora/ gestora directa de vivienda41.

Además, la autoridad metropolitana deberá incluir la vivienda en la formulación de sus estrategias sobre ordenación del territorio, transporte y desarrollo económico.

La experiencia de los gobiernos metropolitanos en otros países ha mostrado que la vivienda no representa una prioridad máxima para este nivel de la administración, al contrario de la planificación territorial, los transportes, el medio ambiente y el desarrollo económico. No obstante, en experiencias anteriores de gobierno metropolitano, paradigmáticas para el Área M etropolitana de Lisboa, la vivienda siempre fue considerada una de las competencias funcionales de la autoridad metropolitana, además casi siempre con competencias de coordinación. La concertación de actores y la búsqueda de soluciones consensuadas, más que la imposición de soluciones, debe ser el principio orientador de esta entidad en el sector42.

En conclusión, la vivienda es considerada en general una competencia funcional secundaria, pero hay alguna conciencia adquirida sobre la necesidad de intervención de un autoridad metropolitana en el sector. 


\subsection{Los transportes}

Uno de los ámbitos, junto al de la ordenación del territorio, de mayor importancia en la intervención de las áreas metropolitanas es, sin duda, el ámbito de los transportes43.

La ausencia de planificación integrada entre el urbanismo y los transportes y la inexistencia de una planificación multimodal de las redes de transportes han generado tanto a escala local como regional una gestión ineficiente eirracional de los diversos medios de transporte que operan en las áreas metropolitanas. El aumento del número de vehículos como consecuencia de los cambios recientes en los ingresos de las familias, las necesidades de desplazamiento, la deficiencia de los sistemas de transporte colectivo y la falta de adecuación de la gestión de las infraestructuras en relación con las necesidades de movilidad, así como la existencia de una política que ha privilegiado la utilización del transporte individual son problemas a los que el área metropolitana debe hacer frente-44.

Tanto en las áreas metropolitanas como en las Grandes Áreas U rbanas portuguesas existen problemas relacionados con la planificación, implementación y gestión de los transportes colectivos locales, urbanos y suburbanos, debiendo en su decisión prever una coherencia funcional y espacial, materia ésta que no se podrá restringir sólo a los municipios incluidos en el sistema referido, sino que deberá tener una lógica más inclusiva e integrada. $H$ ay quien recomienda un nuevo modelo de administración del territorio para la formulación de políticas y medidas adecuadas para la disminución de los desequilibrios existentes. Es necesaria la existencia de una entidad que planifique, coordine y monitorice la gestión de los transportes colectivos en las áreas metropolitanas y en las $G$ randes Áreas U rbanas, fomentando la articulación entre las diversas entidades e impulsando la planificación integrada de las redes de los diversos medios de transporte. Cualquiera que sea el modelo institucional y organizativo a adoptar por esta entidad puede presentar varias denominaciones (autoridad metropolitana, comunidad metropolitana de transportes, empresa metropolitana de transportes), pero tiene siempre que responder a cuatro cuestiones esenciales para conseguir su funcionamiento: ¿Q uién planifica? ¿Q uién financia y cómo? ¿Q uién otorga la concesión de los servicios de transporte y los fiscaliza? ¿Y quién ejecuta?45.

Existe, pues, una incuestionable necesidad de creación de un órgano propio a nivel regional/intermunicipal que, en corresponsabilidad con los organismos de la administración central directamente implicados, asegure la planificación de redes y sistemas, la programación de inversiones, la atribución y fiscalización de concesiones, la definición de política de tarifas y la obtención de los recursos necesarios para el funcionamiento integrado y coherente del sistema.

\section{Los cambios institucionales previstos}

\subsection{Principios generales a considerar en un eventual cambio institucional}

Últimamente se está defendiendo la idea de que «... lasáreas metropolitanas están "heridas" por la incapaci dad de promover la convergencia de orientaciones comunesa los municipiosque lasinte gran (... ), es importante, por eso «...dar un " salto" (...) que pue da de algún modo calificar este espacio de dialogo y concertación» 46 . La cuestión es cómo dar ese «salto».

N os parece que, para ello, el camino pasa sobre todo, independientemente de la determinación del modelo de gobierno más adecuado, por la dotación a las áreas metropolitanas de recursos financieros y humanos, teniendo en cuenta el papel que a ellas les toca desempeñar47.

Todo esto se hace más necesario cuando existe una evaluación francamente negativa del modelo de funcionamiento en vigor. $\mathrm{H}$ ay, por tanto, un consenso amplio en cuanto al mal cumplimiento y la falta de operatividad del modelo actual, debiendo, por eso, evitar clonarlo en otras áreas metropolitanas que se pretendan crear en el país.

La idea común es que los órganos de las actuales áreas metropolitanas no tienen poder, no tienen competencias ni funciones significativas, no disponen de medios importantes y, por eso, no inciden en con la vida cotidiana de los ciudadanos. Además, las áreas metropolitanas nunca tuvieron un protagonismo efectivo en el ámbito de la planificación y de la ordenación del territorio, ámbitos hacia los cuales, como citamos, están especialmente inclinadas. El único poder del que disponen es el poder político que, de hecho, está formado por representantes de los gobiernos autónomos que representan al $40 \%$ de la población portuguesa, sumando el Area M etropolitana de Lisboa y el Área M etropolitana de 0 porto.

D ebe, pues, irse hacia un modelo, cualquiera que sea, que permita un refuerzo de sus poderes, permitiendo que las áreas metropolitanas tengan capacidad para gestionar los problemas e interdependencias territoriales, contradiciendo el modelo actual que es demasiado ambiguo. Un organismo metropolitano deberá tener poderes efectivos, si bien apenas a nivel de coordinación estratégica, incluyendo la definición de la estrategia de desarroIlo, la política de ordenación del territorio, la planificación y gestión de las áreas funcionales, lo que significa que deberá ser una entidad con un estatuto reforzado, que vincule a los gobiernos autónomosy al Estado, debiendo también tener un poder políti- 
co fuerte, o sea, un poder que le permita definir una estrategia, coordinar cierto tipo de opciones municipales y de la administración central y, sobre todo, con capacidad para decidir e imponer el destino de los recursos. Una entidad de éstas, con un poder político fuerte y real, deberá actuar con poderes funcionales restringidos, 0 , si no, deberá tener atribuciones en un número limitado de sectores48.

Del modelo de funcionamiento vigente debe retirarse, al me nos, la experiencia acumulada de relaciones internas particularmente difíciles por la naturaleza y dimensión de las cuestiones y la amplísima representación de los representantes de entidades regionales y locales49.

\subsection{Una propuesta de Ley para la creación y funcionamiento de nuevas áreas metropolitanas}

EI XV Gobierno Constitucional portugués, en la serie de intenciones expresadas en su programa electoral de «estudio y creación de nuevas áreas metropolitanas en las regi ones urbanas emergentes, entregando, racionalizando y planificando su desarrollo sostenido a partir de la voluntad de los munici pios en aquellas creadas según el principio de génesis voluntaria de la organización administrativa plurimunicipal», aprobó, el pasado día 6 de agosto, una propuesta de Ley-M arco, para presentar a la Asamblea de la República, relativa a la institución, estructura y funcionamiento de las nuevas áreas metropolitanas.

Nos parece, pues, oportuno terminar el presente artículo con la indicación de las principales líneas de orientación de la referida Ley-M arco, adivinando, desde ahora, que la presentación para su aprobación en la Asamblea de la República será motivo, ciertamente, para volver a discutir el modelo de organización de las referidas áreas.

Teniendo en cuenta que se trata sólo de una propuesta de Ley y no de una norma dispuesta para entrar en vigor, nos limitaremos a indicar, prácticamente sin comentarios, sus trazos más significativos.

Pasamos, pues, a analizar la citada propuesta.

En los términos del artículo 10 de la propuesta de ley, se distinguen, de acuerdo con el respectivo ámbito territorial y demográfico, dos tipos de áreas metropolitanas: las $G$ randes Áreas M etropolitanas (GAM) que comprenden obligatoriamente un mínimo de nueve municipios e integran, por lo menos, 350.000 habitantes, y las Comunidades U rbanas (ComU rb), que comprenden obligatoriamente un mínimo de tres municipios e integran, por lo menos 150.000 habitantes50, siendo, unas y otras, personas colectivas públicas de natural eza asociativa y de ámbito territorial quetienen como fin la prosecución de los intereses comunes de los municipios que la integran (artícu$1020) 51$.

En lo referente a las atribuciones reconocidas a las áreas metropolitanas, se nota un esfuerzo claro de refuerzo de su poder de decisión. D etermina, así, el artículo 60 que serán atribuciones de las áreas metropolitanas aquellas que les sean transferidas por la Administración central y por los municipios: articular las inversiones municipales de interés supranacional; coordinar actuaciones entre los municipios y los servicios de la administración central, en las áreas de infraestructuras de saneamiento básico y de abastecimiento público; de salud; de educación; de medio ambiente, conservación de la natural eza y recursos naturales; de seguridad y protección civil; accesibilidad y transportes; equipamientos de utilización colectiva; promoción del turismo, cultura y valoración del patrimonio; apoyos al deporte, la juventud y las actividades de ocio; de planificación y gestión estratégica, económica y social; y de gestión territorial en el área de los municipios que la integran 52.

Las grandes Áreas Metropolitanas tienen como órganos propios la Asamblea M etropolitana, la Junta M etropolitana y el Consejo M etropolitano. A su vez, son órganos de las Comunidades Urbanas la Asamblea de la Comunidad U rbana, la Junta de la la Comunidad Urbana y el Consejo de la Comunidad Urbana53.

La propuesta de ley prevé también que, en las GAM , la Junta pueda proponer a la Asamblea el nombramiento de un administrador ejecutivo o la creación de un consejo de administración, compuesto por un número máximo de 3 miembros y en las comUrb, el nombramiento de un administrador ejecutivo, ejerciendo uno u otro órgano las competencias de gestión corriente que le fueran delegadas por la Junta.

Se prevé, también, que las áreas metropolitanas estén dotadas de servicios de apoyo técnico y administrativo, preparados para recoger y sistematizar la información y para elaborar los estudios necesarios para la preparación de las decisiones o las deliberaciones, como para promover la respectiva ejecución.

Las Áreas M etropolitanas permanecen sujetas al régimen de tutela administrativa prevista para los gobiernos autónomos locales y sus cuentas están sujetas al análisis y examen del Tribunal de Cuentas.

La propuesta de ley contiene también un conjunto de disposiciones relativas a la extinción (fusión, escisión y liquidación) de las áreas metropolitanas y un conjunto de disposiciones finales transitorias relativas, principalmente, a las comisiones que establecen las nuevas áreas metropolitanas y a la adaptación del régimen de las áreas metropolitanas de Lisboa y 0 porto al nuevo régimen propuesto. La eventual aprobación de esta propuesta de ley en la Asamblea de la República implicará la revocación de la Ley $n .044 / 9154$. 
* Profesora de la Facultad de D erecho de la Universidad de Coimbra (Portugal). La traducción española de la versión original portuguesa ha sido realizada por Carmen Pin ed A N EBOt, Investigadora del Departamento de Ciencia Política y Relaciones Internacionales de la Universidad Autónoma de M adrid.

1 Sobre estos y otros problemas que surgen en las grandes áreas urbanas en Portugal; cfr. Sistema U rbano N acional. Cidades M édias e Dinâmicas Territoriais, 1999, Vol. 3, DGOTDU, p. 14.

2 Diego Freitas do Amaral, Curso de Direito Administrativo, 2ạ Edição, Vol. I, Coimbra, Almedina, 1996, p. 506.

3 Existen, de hecho, problemas específicos de las grandes ciudades consideradas en sí mismas, tanto de naturaleza política - las grandes ciudades, y en especial las capita les, constituyen en cierta forma una amenaza al poder central, siendo por eso normal someterlas a un régimen de control más exhaustivo por parte de éste- , como de na turaleza técnica (de organización, de eficacia, de rendimiento de la estructura administrativa, etc... ). Cfr. Diego Freitas do Am ARAL, Curso de Direito Administrativo, cit., p. 507.

4 La decisión sobre los servicios y los intereses a gestionar integradamente a un nivel superior al municipal tendrán que ser analizados caso a caso, aunque se puede afirmar, con algún grado de certeza, que servicios que justifican nítidamente una gestión territorial más amplia que la gestión municipal son los servicios en red (saneamiento básico, transportes), la ordenación del territorio y la planificación territorial, el me dio ambiente, en resumen, las grandes funciones que dan consistencia a una organización metropolitana.

5 Sobre los cuatro componentes a los que nos hemos referido en el texto para determinar el modelo de organización de las áreas metropolitanas cfr. José António SANTOS/ Fernando N unes da SIlva/ Ana Rita Ro SAdo/ Paula Paulin O/ Vanda Lo PeS, «Formas de G estão de Áreas M etropolitanas», en Território e Administração. Gesão de Grandes Á reas U rbanas. Actas do Seminário, Lisboa, 2001, Fundação para a Ciência ea Tecnologia, M inistério da Ciência eda Tecnologia, p. 28.

* Corporación administrativa que goza de autonomía.

6 Sobre esta cuestión cfr. Cfr. José António Santos/ Fernando N un ES DA SILVA/ Ana Rita Rosad o / Paula PAulin o/ Vanda LO PES, «Formas de G estão de Áreas M etropolitanas", cit. p. 29 y sS. y Fernando Alves Co RREIA, «Alguns Problemas Jurídico-Administrativos das Á reas M etropolitanas", en Espaço Imperfeito, Forum Portucalense.

$7 \mathrm{Cfr}$. Fernando Alves CO RREIA, «Alguns Problemas Jurídico-Administrativos das áreas M etropolitanas", en Espaços Imperfeitos, Forum Portucalense.

8 Puede, además, afirmarse que no existe ni siquiera acuerdo teórico sobre el concepto de área metropolitana o sobre la definición de sus límites; ni para al gunas de las cuestiones que aquí discutiremos sobre cuál es la mejor figura institucional para dirigirlas.

9 El fenómeno del crecimiento de núcleos adyacentes junto a las grandes ciudades se debe a varias razones, especialmente, al precio de los alquileres en el centro de las ciudades, que forzó a la mayor parte de las personas que en ella trabajan a buscar vivienda en los al rededores.

10 El sistema urbano portugués presenta un fuerte desequilibrio que se manifiesta en la falta de centros de densidad media (principalmente en el interior, donde ninguna aglomeración alcanza los 50.000 habitantes) y una evidente litoralización de la población, una franja de $400 \mathrm{kms}$ de largo que se extiende de Viana do Castelo hasta Setúbal concentra cerca del $85 \%$ de la población urbana y abarca las principales áreas urbanas incluyendo las dos metrópolis, en cambio, el interior permanece desierto). A su vez, la formación de aglomeraciones ha sido difícil por las deficiencias de accesibilidad (aunque han mejorado significativamente en los últimos años) y porque existe una nítida bipolaridad, difusión de urbanización y falta de cohesión y complementa riedad entre la mayor parte de las áreas urbanas. Cfr. M aria Júlia FERREIRA/ Ana Rita ROSAD 0, «As Grandes Áreas Portuguesas. Conceitos e D elimitação Espacial», en Te rritório e Administração, cit., p. 46-47.

11 M aria uúlia FerReIRA e Ana Rita RoSAD0, ob. cit., p. 52, definen como grandes áreas urbanas aquellas que tienen más de 150.000 habitantes, incluyendo por lo menos tres ayuntamientos, tienen densidad de población y población urbana elevadas y cuyo grado de polarización del centro es de fuerte a medio. La Dirección General de O rdenación del Territorio y Urbanismo las define, a su vez, como «conjuntos de cen- tros urbanos, especialmente próximos y distribuidos de forma no lineal, con lógicas de organización espacial complementarias concertadass. Se trata, según las autoras antes referidas, de áreas que tienen ya al gunas características que las aproximan a las áreas metropolitanas - dimensión demográfica, intensidad del fenómeno urbano, dinamismo económico traducido en la capacidad de polarización, etc... Aquí se incluyen las áreas centradas en Aveiro, Braga, Faro y Funchal.

12 Cfr. M argarida Pereira/ Carlos N un es da Silva, «As Grandes Áreas U rbanas. Contributos para a D efinição de Alternativas ao M odelo Institucional Vigente», en Território eAdministração, op. cit., p. 87.

13 Esta conflictividad entre los dos niveles (municipal y metropolitano) se ha observado en otros países europeos donde este doble nivel existía y concurría, de modo especial, para «legitimar»el desmantelamiento, por parte del entonces $G$ obierno de $M$ argaret Thatcher, de la autonomía del Gran Londres, que, a pesar de su capacidad técnica y su vigor político, no consiguió al canzar consenso con sus «distritos urbanos», tanto para la red viaria y localización del terciario del nuevo plan director, como para las acciones de vivienda y renovación o recuperación. Cfr. N uno Po RTAS, «A Instituição Metropolitana», en Cadernos M unicipais, n- 40/41, 1987, p. 55.

14 Este fenómeno llego a darse en el caso de Lisboa, cuyo municipio incorporó a los antiguos ayuntamientos de Algés e O livais.

15 Cfr. Diogo Freitas do Am aral, Curso de D ireito Administrativo, cit., p. 513. De bido a esta configuración legal de naturaleza jurídica de las áreas metropolitanas, este autor llega a cuestionar la constitucionalidad de la opción hecha por nuestro legislador a tenor del referido n- 3 del artículo 236 de la Constitución que, según él, parece exigir la naturaleza autónoma de estas entidades y, por tanto, como mínimo, la elección directa da su asamblea deliberativa.

${ }_{16} \mathrm{Cfr}$. Jorge LACÃo, in Caderno M unicipais, n. -53, p. 90 e Fernando Alves CoRREIA, «Alguns Problemas Jurídico-Administrativos das Áreas M etropolitanas», ambos citados por Jorge A. B. Ferreira, Á reas M etropolitanas e outras G randes Áreas U rbanas, Breve Nota Introdutória, Inédito.

17 Cfr. Mário RuI DE O LIVEIRA M ARTINS, «A Administração das Áreas M etropolitanas: Análise Comparativa de Algumas Experiências Europeias», en Espaço Imperfeito, Forum Portucalense.

18 A su vez, contra el modelo de creación de una entidad autónoma se ha presentado el argumento de que su institucionalización crearía una impracticable yuxtaposición de instituciones y de órganos - parroquia, municipio, área metropolitana, una eventual región administrativa e, inevitablemente, un Gobierno Central- , lo que llevaría no a un sistema de cooperación (como se pretende), sino a un sistema de conflictividad (que se quiere evitar).

Por otro lado, una visión contraria a la creación de las áreas metropolitanas como entidades autónomas se basa en el hecho de que puede comprometer la real autonomía de las autonomías municipales, si sus atribuciones se tradujeran en atribuciones municipales que sean transferidas al área metropolitana. La autonomía metropolitana sólo no plantearía esta objeción si fuera instituida a costa de transferencia de atribuciones del Estado, respetando simultáneamente la esfera de atribuciones propias de las autonomías/municipios.

19 Si esto es así en general, esta solución asume un significado especial en el contexto de las Ilamadas «grandes áreas urbanas», pues así es sentida la necesidad de resolución conjunta de varios intereses y problemas comunes a los diferentes municipios.

20 Los artículos citados en este punto sin indicación del título deben considerarse hechos por la Ley n-44/91.

${ }^{21}$ Articulación de intereses es, pues, no esencialmente, la función específica del área metropolitana. La necesidad de coordinar, compatibilizar 0 articular mejor las estrategias de acciones sectoriales que tienen o pueden tener su sede en los municipios ha sido un importante argumento presentado a favor de las áreas metropolitanas, sirviendo estas precisamente de base para la cooperación intermunicipal y con el nivel administrativo «superior» (Región Administrativa o G obierno C entral).

22 La Comisión de Coordinación Regional es un órgano desconcentrado del Estado. 23 Éstos son libremente liberados y exonerados por los miembros del Gobierno que los tutelan.

24 Cfr. Nuno Portas, op. cit., pp. 56-57. 
25 Este aspecto se agrava por el hecho de que los miembros del área metropolitana son, en primer lugar, políticamente responsables a nivel municipal, lo que les lleva a prescindir de decisiones que de al guna manera penalizan a sus municipios. $\mathrm{Cfr}$. M argarida Pereira/ Carlos N un ES da SILva, «As Grandes Áreas U rbanas æC ontributos para a D efinição de Alternativas ao M odelo Institucional Vigente», en Território e Administração, cit., p. 83.

26 Un ejemplo típico de la capacidad de formalizar estrategias a escala metropolitana es el de la Junta M etropolitana de 0 porto, que posee el $60 \%$ de capital del metro de la respectiva Área M etropolitana y la mayoría del Consejo de Administración. La empresa va a realizar una de las mayores obras de transporte urbano en toda la Europa comunitaria, obra que fue iniciativa exclusiva de la Junta M etropolitana de 0 porto que la diseño, pensó y ejecutó.

27 En una definición extensiva, la Administración autónoma consiste en la adminis tración de los intereses públicos propios de ciertas colectividades 0 agrupaciones infraestatales (de natural eza territorial, profesional u otra), por medio de corporaciones de derecho público o de otras formas de organización representativas, dotadas de poderes administrativos que ejercen bajo su propia responsabilidad, sin sujeción a un poder de dirección o de superintendencia del Estado (a través del Gobierno), en forma de tutela de merito. D e esta definición salen los principales elementos constitutivos del concepto de administración autónoma que son varios y acumulativos. una entidad territorial u otra dotada de especificidad dentro de la comunidad nacional global; la real ización de intereses específicos de esa entidad infraestatal; la administra ción por los propios administrados (sea directamente, o por medio de sus representantes); y la autonomía de acción frente al Estado. En las áreas metropolitanas falta, no obstante, el tercer elemento referido.

28 En efecto, según el artículo 20 de la Ley $27 / 96$, la «tutela consiste en la verificación del cumplimiento de las leyes y reglamentos por parte de los órganos y servicios de las autonomías locales y asimiladas».

${ }^{29}$ A hora el régimen legal de la tutela sobre las áreas metropolitanas es el mismo que el de las autonomías locales, pero no se puede afirmar lo mismo en cuanto a su régimen constitucional. Efectivamente, la Constitución de la República Portuguesa re serva un régimen propio (restrictivo) para la tutela del Estado sobre las autonomías locales, determinando que la tutela que el gobierno ejerce sobre ellas, cuando son intereses locales, es apenas una tutela de legalidad (artículo 242, n- 1, de la CPR), de biendo ser consideradas anticonstitucionales las disposiciones legales que amplían, en el ámbito de las atribuciones propias de las autonomías, los poderes de intervención del Estado. No obstante, como las áreas metropolitanas no son autónomas, no están sujetas a este régimen constitucional restrictivo.

30 C fr. Sistema U rbano N acional. Cidades M édias e D inâmicas Territoriais, cit., p. 17. Un error en que hemos caído sucesivamente consisteen desviar las grandes inversiones en obras públicas hacia las dos áreas metropolitanas. La realización de la Expo 98 (Lisboa) y la iniciativa 0 porto Capital Europea de la Cultura (0 porto) son buenos ejemplos de esto. Sobre la influencia altamente negativa de estas decisiones desde el punto de vista de la ordenación del territorio, cfr. M anuel LOPES PORTO, O rdenamento do Território Face aos D esafios da Competitividade, Almedina, Coimbra, 1996.

31 Como afirma Yves M ADIOT, Io mismo que cuando las entidades administrativas utilizan el procedimiento clásico de decisión unilateral, a través de la aprobación de figuras de planificación, lo llevan a cabo con una mezcla de negociación y de discusión que hacen de la decisión una actuación concertada, en su contenido y en su ejecución. Yves M AdIOt, L'Aménagement du Territoire, 2ª ed., M asson, 1993, pp. 23-24.

32 Los que defienden la urgencia de la configuración de las áreas metropolitanas como autonomías supramunicipales afirman que la planificación estratégica, como piedra de toque de la realidad metropolitana o ciudadana justificaría, por sí sola, la creación de un ente autónomo municipal.

33 Los instrumentos de desarrollo territorial se encuentran definidos en la Ley de Ba ses de Política de 0 rdenación del Territorio y de U rbanismo como instrumentos de carácter estratégico y de definición de las grandes opciones con relevancia para la organización del territorio, estableciendo las directrices de carácter genérico sobre el modo de uso del mismo, e identificando el cuadro de referencia a tener en considera ción en la elaboración de los instrumentos de planificación territorial [artículo 8a punto a), de la Ley de Bases]. Además de los planes intermunicipales, son instrumentos de desarrollo territorial el Programa Nacional de Política de O rdenación del Te rritorio (instrumento que proporciona el cuadro estratégico para la ordenación del te rritorio nacional establece las directrices a considerar en la ordenación regional y municipal, y la compatibilidad entre los diversos instrumentos de política sectorial, indicando en sus directrices y orientaciones el modelo de organización espacial - artículos $70, n-2$, punto a) y $90, n-2$, punto a)- y los planes regionales de ordenación del territorio (instrumentos que definen el cuadro estratégico para la ordenación del espacio regional en estrecha articulación con las políticas nacionales de desarrollo económico y social, estableciendo las directrices orientadoras de la ordenación municipal - artículo 7ㅇ, n-2, punto b)-

34 Los planes intermunicipales están formados por una descripción y por un conjunto de piezas gráficas ilustrativas de las orientaciones substantivas, pudiendo estar acompañadas, en función de los respectivos ámbitos y objetivos, por un plano de encuadramiento, incluyendo el área de intervención y el resto del área que incluye al conjunto de los municipios, la identificación de los valores culturales y naturales a proteger; la identificación de los espacios agrícolas y forestales con relevancia para la estrategia intermunicipal de desarrollo rural, los programas de acción territorial relativos, fundamentalmente, a la ejecución de las obras públicas determinadas por el plan y el plan definanciación - artículo 630-

35 LOS PROT son fundamentalmente instrumentos programáticos y de estrategia y, su formulación de propuestas concretas tiene cuatro partes: la estrategia de desarrollo económico, social y territorial para la región respectiva; el modelo territorial, por tanto, la organización del territorio materializada a través de sus grandes tendencias y la estructuración de las diversas redes (de transportes, ecológicas); las normas agrupadas para la planificación municipal y sectorial de la Administración central; y la programación de intervenciones vinculando, por tanto, acciones e inversiones de la Administración Pública.

36 Sobre el nuevo regimen de los PROT, cfr. Fernanda Paula 0 LIVEIRA, «Alguns Aspectos do Novo Regime Jurídico dos Planos Regionais de 0 rdenamento do Território. Em Especial, a Q uestão da sua Eficácia Jurídica», en Revista Jurídica do U rbanis mo eAmbiente, n-s 11/12, 1999, p. 69 y ss.

37 Sobre este aspecto cfr. «Planeamento e G estão do Turismo em Áreas M etropolitanas e G randes A reas U rbanas», en Território e Admi nistração, op. cit., p. 233 y sS.

$38 \mathrm{M}$ aria Júlia FerReIRA, «A H abitação em Áreas M etropolitanas», en Território eAdministração, cit., p. 259.

39 M aria Júlia FERREIRA, «A H abitação em Áreas M etropolitanas», en Território eAdministração, cit., p. 259.

40 Carlos N un ES DA SILva, «Política(s) de H abitação: coordenação estratégica em áreas metropolitanas», en Território e Administração, cit., p. 280.

41 Su función debe ser efectivamente estratégica, debiendo tener la capacidad de influir en las decisiones sobre el modo en que los recursos son utilizados en el sector de la vivienda, mas no debiendo comprometerse en la provisión directa de las viviendas. 42 Carlos N un ES DA SILvA, «Política(s) de H abitação: coordenação estratégica em áreas metropolitanas», cit., p. 287.

43 Fernando N un ES DA SILVA/ N uno M ARQues da Costa, «Transportes Públicos U rbanos - a Situação em Portugal», en Território e Administração, cit., p. 316

$44 \mathrm{D}$ espués de las áreas metropol itanas, este fenomeno está también presente en otras áreas urbanas de gran dimensión, donde la movilidad ha crecido en los últimos años, como es el caso de Coimbra, Braga, Aveiro y Faro. Cfr. Fernando N unes da SILva/ N uno M ARQUES DA COSTA, «Transportes Públicos U rbanos - a Situação em Portugal», cit., p. 316.

45 Fernando N uneS DA Silva/ N uno M ARQues da Costa, «Transportes Públicos Urbanos - a Situação em Portugal», cit., p. 330.

46 José SARAIVA, Áreas M etropolitanas, como evitar o definhamento?, en Cadernos M unicipais, $n=72,2000$, p. 16 ess.

47 J.P. BAPTISTA D IAS, «Regionalização e Redelimitação das Atribuições dos Vários N íveis do Poder Político», en Interacçōes. Revisa do Instituto Superior de Serviço Social deCoimbra, no 4, 1996, p. 100.

48 Las áreas metropolitanas están también particularmente bien situadas para poner en funcionamiento un observatorio de fenómenos metropolitanos que facilite y estimule políticas, como la sanidad o la seguridad, el medio ambiente e igualmente la educación.

49 En efecto, en las áreas metropolitanas están presentes al gunos de los mayores municipios portugueses, con intereses muchas veces divergentes.

50 Los municipios incluidos en la misma área metropolitana deben estar unidos por un nexo de continuidad territorial ( $n-1$ do artigo 30 ). 
51 La creación de las GAM y de las C omU rb depende del voto favorable de las Asambleas M unicipales, sobre propuesta de las respectivas cámaras municipales, no pudiendo los municipios pertenecer a más de un área metropolitana. D espués de su entrada en la respectiva Área M etropolitana, los municipios constituyentes están obligados a permanecer integrados en la misma durante un período de cinco años, bajo pena de perder todos los beneficios financieros y administrativos y de no poderse integrar en otra Área M etropolitana distinta a la que estaba durante un período de 2 años. D espués de los cinco años, cualquier municipio puede abandonar el Área Metropolitana en que está integrada, después de que la respectiva asamblea municipal lo decida por una mayoría de dos tercios.

El abandono de uno o más municipios que interrumpa la continuidad territorial sólo producirá la extinción del Área M etropolitana cuando setraduzca en la reducción del número mínimo de municipios previsto.

51 La propuesta de ley prevé expresamente como competencia de la Junta, en el ám- bito de gestión territorial, la promoción y elaboración de los Planes Regionales de O rdenación del Territorio y la participación en la elaboración de los Planes Especiales de 0 rdenación, en las GAM ; y la promoción y elaboración de los Planes Intermunicipales de 0 rdenación del Territorio y participación en la elaboración de los Planes Especiales de 0 rdenación, en los Comurb.

53 La Asamblea está constituida por miembros el egidos por las asambleas municipales de los municipios que componen la respectiva área metropolitana, en número impar superior al triple de los municipios quela integran, con un máximo de 55. A su vez, la Junta está formada por los presidentes de las cámaras municipales de cada uno de los municipios integrantes que eligen, de entre ellos, un presidente y dos vicepresidentes. $54 \mathrm{~N}$ ota del coordinador: Cuando este número de la revista ya estaba en pruebas de imprenta, la autora de este artículo, sobre Portugal, nos ha comunicado la aprobación de la Ley 10/2003, de 13 de mayo. El texto final de la Ley es sustancialmente similar al del Proyecto descrito en este artículo. 